\title{
Effects of Moral Self, Self Esteem and Parental Bonding on Delinquency among Young People in Hong Kong
}

\author{
Po F. Cheng and Christopher H.K. Cheng
}

\author{
City University of Hong Kong, Hong Kong
}

\begin{abstract}
This study was designed to investigate the effects of global self-esteem, moral self, and parental bonding on youth's delinquency. A sample of young Chinese adults $(\mathrm{N}=200)$ were drawn from public areas such as playgrounds and campus. Respondents were to complete a questionnaire consisted of the General Self, Moral Self, Parental Bonding, and Behavior Checklist on an individual basis. As a result, males reported higher delinquency as well as general selfesteem than females. Among the demographic variables, gender was found to significantly predict delinquency. For the self variables, moral self but not global self-esteem was found to predict delinquency significantly, even when the effect of gender was being controlled. Among the parenting aspects (authoritarianism, protectiveness, care), protectionism significantly predicted delinquency, while parental care and authoritarianism did not. These findings confirmed the need of considering multidimensional aspects of self-esteem and the cultural perspective in explaining the parental impacts on delinquency.
\end{abstract}

Keywords: Moral self, self-esteem, parental bonding, delinquency.

\section{INTRODUCTION}

While Hong Kong has reportedly low overall crime rates, less violent crimes (such as triad related crimes, thefts, narcotics offences, indecent assaults) are still prevalent or even increasing (Police in Figures, n.d.). Moreover, the proportion of youth offenders (aged 16 $1020)$ was high on certain less serious crimes. For example, number of youth arrested for triad related crimes and robberies was around $48 \%$ and $40 \%$ of total arrests in the categories respectively in year 2013 .

Research has shown that childhood problems were responsible for a wide range of adverse psychosocial outcomes in adulthood, including delinquency, poor mental health and interpersonal relationships (Fergusson, Horwood, \& Ridder, 2005). Delinquent involvement in teenage was found to be associated with young adults' crime involvement and had a persistent effect in later years (Mason et al. 2010). From a developmental psychological perspective, childhood cognitive and affective experiences with their significant others and about themselves will likely extend to development in adult life (Sroufe, 2005). Psychosocial variables such as parental care, good relationship with peers, sense of achievement, and self-esteem are believed to be protective factors for the child against adverse development (e.g. Cheung \& Cheung, 2007; Hoeve, Dubas, Eichelsheim, van der Laan, Smeenk, \& Gerris, 2009). The present study aimed at delineating the effects of perceived

*Address correspondence to this author at the Department of Applied Social Sciences, City University of Hong Kong, 83 Tat Chee Avenue, Kowloon, Hong Kong; Tel: +852 3442 8832; Fax: +852 3442 8991; E-mail: sshkc@cityu.edu.hk experience with parents during childhood, specifically parental bonding, and the sense of self-worthiness (self-esteem) on delinquency of young adults.

\section{Delinquency \& Self-Concept}

The association between self-concept (or generally termed self-esteem) and delinquency has been widely investigated (e.g. Church, Tomek, Bolland, Hooper, Jaggers, \& Bolland 2012; Donnellan, Trzesniewski, Robins, Moffitt, \& Caspi 2005; Kaplan, 1978; Lee \& Lee 2012). Yet, both the strength and direction of the relationship, if any, seem to be inconclusive. In some studies, self-esteem was found to be positively correlated with delinquency (e.g. Caldwell, Beutler, Ross, \& Silver, 2006), while some suggested a negative correlation between self-esteem and delinquency (Lee \& Lee, 2012). Lee and Lee (2012) found that delinquency was negatively correlated with subsequent self-esteem among Korean adolescents. Donnellan and colleagues (2005) showed that, in both cross-sectional and longitudinal studies, there was a robust relationship between low self-esteem and externalizing problems such as aggression and delinquency even after controlling for confounding variables such as IQ, socioeconomic status, parentchild and peer relationships. On the other hand, Cheng (2014) delineated the relationship between self-esteem and delinquency and found that the relationship was of curvilinear nature, suggesting that the relationship between self-esteem and delinquency could be more complex and not denoted by correlational analysis. Lo and colleagues (Lo, Cheng, Wong, Rochelle, \& Kwok, 2011) also found that delinquents could have relatively low self-esteem when they were in the emerging stage 
of delinquency, and they would gradually build up their self-esteem through association with delinquent peers who would serve as their role models. Moreover, Van de Schoot and Wong (2012) found that the strength and direction of association between self-concept and delinquency depended on the domain of self-concept.

A way to better understand the relationship between the self and delinquency is to look into the specific facets/domains of the self. Among different selfconcepts, Hardy, Walker, Olsen, Woodbury, and Hickman (2014) found an important role of moral identity in adolescent functioning, such that moral ideal self negatively predicted externalizing symptoms. Tarry and Emler (2007) found evidence suggesting that selfreported delinquency was predicted by moral values. Cheng (2014) also found that moral self was more predictive of delinquency than a global measure of selfesteem did. To sum up, while the relationship between self-concept and delinquency has been posited for a long time, there are still unanswered questions about its nature. The relationship could be positive or negative, linear or non-linear, and it could be more salient if specific domain or facet of the self (e.g. moral self) instead of the global self (self-esteem) was addressed.

\section{Delinquency \& Parenting}

Parenting variables have been considered as one of the most significant predictors of negative outcomes of the child. A meta-analysis of 161 published and unpublished manuscripts conducted by Hoeve and colleagues (Hoeve et al., 2009) revealed that there was a strong link between parental monitoring, psychological control and negative aspect of support, and delinquency, these parenting factors totally has accounted for up to $11 \%$ of the variance in delinquency. Stoltz, Londen, Dekovic, Prinzie, de Castro, and Lochman (2013) found that a positive parent-child relationship was associated with less aggression. According to Stoltz et la (2013), parentchild relationship could 'buffer' the development of more serious aggressive behavior. In a study with samples of African Amercian and Caucasian American, Huey and colleagues (2000) found that positive changes in family relations (such as family cohesion, family cohesion, parental monitoring) were associated with reduction in delinquent behaviors. By and large, parenting experiences of a child have been found to be associated with his/her later development in adulthood.

Perhaps the most influential work on parenting can be attributed to John Bowlby (1969, 1973, 1980), Mary
Ainsworth (1978), and Diana Baumrind (1971). While the details of their great work are outside the scope of this paper, their theories and models have prompted decades of research. The key concepts of Bowlby's and Ainsworth's writings are about the affectional bond between parent (mother) and the child. Bowlby emphasized the internal working models of infants which are being formed as a result of the infant's exploration and attachment relationship with the caregiver, primarily the mother. Through analyzing the children's behavior in the Strange Situation episodes, Mary Ainsworth categorized the children's relationship attachments into securely attached, insecure / avoidant, insecure / ambivalent. Diana Baumrind focused on the roles of parents and described parenting along the demandingness (control) and affectionate (responsiveness) dimensions. Under these two dimensions four types of parenting styles are classified, namely, authoritarian, authoritative, indulgent, and neglectful. Both authoritarian and authoritative parents place limits and controls on their children, but authoritarian parenting is of a more restrictive and punitive style, while authoritative parents encourage their children to be independent and are more affectionate and warm.

From an epidemiological perspective Parker (1990) identified two principal dimensions underpinning the parenting characteristics regarding child development and parent-child attachment, i.e. care and protection / control. The original Parental Bonding Instrument (PBI) (Parker, Tupling, \& Brown, 1979) was developed to measure the two dimensions - Care and Overprotection. Care refers to the degree of warmth and affection, whilst Overprotection measures parental intrusion and control. Later research (Kendler 1996) discovered a third factor - authoritarianism, which was originally embedded in the Overprotection dimension. Authoritarianism refers to parental control that is restrictive and discourages the child's autonomy.

In Western societies, parenting variables such as care, secured attachment, authoritative parenting are widely considered as conducive of children's later positive development, while insecure, authoritarian controlling parenting is associated with negative outcomes. This notion is generally supported by research findings on Western samples (e.g. Maziti, 2014; Sartaj \& Aslam, 2010; Sroufe et al. 2005; Strage \& Brandt, 1999). However, cross-cultural studies suggested that the effect of parenting on children's outcomes may not be as straight forward. 
What defines good parenting could be different across different cultures. Children from different cultural backgrounds may have different understanding of what parental support or control means. The research of García and Gracia (2009) suggested that in the Spanish cultural context, the optimum style of parenting is indulgent parenting, and adolescents who perceived their parents as indulgent scored more positively on all measures of self-esteem when compared with those who characterized their parents as authoritarian or neglectful. There was no significant difference on measures of problem behavior (school misconduct, delinquency, and drug use) between adolescents from indulgent families and those from authoritative families. Martínez, García, and Yubero (2007) have cited several studies which showed that parenting practices have different meanings and implications for children depending on the sociocultural context in which these practices occur. In particular, Martínez et al. pointed out that authoritative parenting is not associated with optimum self-esteem in Brazil. Similarly, researchers in Hong Kong found that family variables such as secure attachment to parents may not be significant predictors of deviant behavior (Cheung, 1997).

While there is a good volume of literature on the relationship between delinquency and self-esteem, and the relationship between delinquency and parenting, few studies have investigated the effects of both the parenting factors and self-esteem on delinquency simultaneously. Furthermore, while self-esteem (the global domain of the self) was studied extensively in delinquency research, inclusion of moral self (self evaluation on the moral facet) was rarely found. While it is widely accepted that parenting and the child's selfconcept and behavioral outcomes should be interrelated, it is not known whether general selfesteem or specific facet of the self (such as moral self), and whether overall parenting or specific dimensions of parenting (e.g. control, over-protection) should be conducive of child's negative behavioral outcomes (delinquency).

\section{METHOD}

\section{Participants}

This study targeted at young persons (aged 18 to 25 ) in Hong Kong. Totally 163 young people were conveniently sampled from youth centers, playgrounds, food courts, cafes and fast food shops, and 37 students were drawn from a university campus in Hong Kong. The sample included 114 males and 86 females, 77
(38.5\%) of them were below 20 years old, 114 (57.0\%) fell between 20 to 25 years old, and $8(4.0 \%)$ were between the ages of 26 to 29 . One respondent did not report his age.

\section{Instruments}

The questionnaire consisted of four sections including 1) self-esteem and moral self, 2) parental bonding, 3) daily behavior checklist, and 4) demographic variables including age, gender, occupation, domestic income. The questionnaire was in the Chinese language.

\section{Self-Esteem and Moral Self}

The General Self (GS) and Moral Self (MS) subscales of the Chinese Adolescent Self-Esteem Scales (CASES) (Cheng \& Watkins, 2000) were used to measure global self-esteem and moral self-concept respectively. Each subscale consisted of 8 items and it adopted a 5-point Likert Scale from 1 (strongly disagree) to 5 (strongly agree). The CASES was emicetically developed in the Chinese language to assess multidimensional self-concept of young Chinese people (Cheng 1997), and has been widely adopted in studies with Hong Kong and Macau samples (EMB 2003; Lo et al. 2011). The scale has demonstrated good psychometric properties in terms of construct validity and reliability (Cheng \& Watkins, 2000, Wong \& Watkins 2001). The Cronbach's alpha coefficients of GS and MO in this study were .89 and .79 respectively, suggesting high internal consistency reliability.

\section{Parental Bonding}

The Chinese version (Shu, Lo, \& Lung, 1999) of the 16-item version (Kendler, 1996) was adopted, which was based on the original Parental Bonding Instrument (PBI) (Parker et al., 1979). Respondents were asked to rate on a 4-point scale from 0 (very unlike), 1 (unlike), 2 (like) to 3 (very like) about their feeling of bonding with mothers and fathers. The PBI has three subscales, namely, Care, Authoritarianism, Protectiveness. The three subscales have shown good internal consistency reliability as indicated by Cronbach's alpha ranging from .74 to .88 .

\section{Daily Behavior Checklist}

A behavior checklist consisting of 33 items was developed with reference to several studies on delinquency (Cheng 2014; Cheung \& Cheung, 2008; Le, Monfared, \& Stockdale, 2005; Lo et al. 2011). The items include 21 items on delinquent behaviors (e.g. 
stealing, physical bullying, gambling) and 12 positive or neutral items (e.g. sports, browsing social media websites) (see Appendix for the list of behaviors). Respondents were to report the frequency of having these behaviors in the past three months on a 5-point scale, from 1 (never) to 5 (always). A total delinquency score (TD) was computed by adding the scores of the 21 delinquent items. Responses on the neutral or positive items were not scored. The internal consistency reliability of the TD scale was high (Cronbach's alpha $=.848$ ).

\section{Procedures}

Ethics approval was obtained from the university college research committee concerned. Research staff randomly approached young people in playgrounds, basketball courts, food courts, café, fast food shops and a youth centre to participate in the study. The targeted participants were briefed of the objectives of the study and were assured of confidentiality and anonymity. They were to sign the informed consent form before administration of the questionnaire. The questionnaire was completed on an individual basis and handed back to the research staff. The whole procedure took around twenty minutes.

\section{RESUTLS}

\section{Descriptive Statistics}

The most commonly reported delinquent behaviors were verbal argument with parents, speaking foul language, buying pirated goods or illegal downloading, and watching pornographic materials. A total of $41 \%$ of respondents reported that they sometimes argued with their parents while $15.5 \%$ often or always argued with their parents. Speaking foul language was one of the most salient behaviors, having $26.5 \%$ sometimes speaking foul language, $38 \%$ often or always speaking foul language. Illegal downloading or buying pirated products ranked the third most common delinquent behavior, $43.2 \%$ reported they sometimes, often, or always download or buy pirated products. Watching or reading pornography materials ranked the fourth with $26.6 \%$ of respondents reported that they sometimes, often or always read/watch materials of pornographic nature.

Descriptive statistics on self-esteem, moral self, parental bonding, and delinquency were shown in Table 1. Significant gender differences were only found on general self-esteem (GS) and delinquency (TD) but not on other measures. Males reported a higher general self-esteem than females (Cohen's $d=.28, p<$ $.05)$ as well as higher delinquency than females (Cohen's $d=.802, p<.01$ ). Other than these two variables, male and female participants did not show significant differences.

\section{Relationship between Self, Parenting, and Delinquency}

Pearson's correlation analysis of all measured variables was shown in Table 2. Total delinquency (TD) was correlated negatively with moral self (MO) $(r=-$ $.16, p<.05)$ but not with any other measures, despite that general self-esteem (GS) and moral self (MS) were correlated $\left(r=.51^{* *}, p<.01\right)$. Regarding the relationship between self-esteem and parental bonding, self-esteem was positively correlated with both father's and mother's caring ( $r=.37$ and .36 respectively) but negatively with father's and mother's authoritarianism ( $r$

Table 1: Descriptive Statistics of Self-Esteem, Moral Self, Parental Bonding and Delinquency Behavior by Sex

\begin{tabular}{|c|c|c|c|c|}
\hline Variables & $\begin{array}{c}\text { Male } \\
\text { M (SD) }\end{array}$ & $\begin{array}{c}\text { Female } \\
M(S D)\end{array}$ & $t$-test & $\begin{array}{l}\text { Effect Size } \\
\text { (Cohen's d) }\end{array}$ \\
\hline General Self & $28.79(6.31)$ & $27.07(5.74)$ & $1.98^{*}$ & .285 \\
\hline Moral Self & $30.41(4.75)$ & $31.00(3.44)$ & $-1.00 \mathrm{~ns}$ & -.142 \\
\hline Paternal Care & $11.33(4.73)$ & $11.39(4.87)$ & $-.082 \mathrm{~ns}$ & -.012 \\
\hline Paternal Authoritarianism & $3.61(2.79)$ & $3.37(2.46)$ & $.606 \mathrm{~ns}$ & -.091 \\
\hline Paternal Protectiveness & $4.59(3.14)$ & $4.85(2.57)$ & $-.645 \mathrm{~ns}$ & -.091 \\
\hline Maternal Care & $13.75(4.29)$ & $13.72(4.24)$ & $.055 \mathrm{~ns}$ & .007 \\
\hline Maternal Authoritarianism & $3.53(2.79)$ & $3.91(2.46)$ & $-1.01 \mathrm{~ns}$ & -.144 \\
\hline Maternal Protectiveness & $5.69(3.55)$ & $5.69(2.56)$ & $-.01 \mathrm{~ns}$ & .000 \\
\hline Total Delinquency & $36.76(10.22)$ & $29.79(6.84)$ & $5.649^{* *}$ & .802 \\
\hline
\end{tabular}

${ }^{*} p<.05,{ }^{* *} p<.01, \mathrm{~ns}=$ non-significant. 
Table 2: Correlation between Self-Esteem, Moral Self, Parental Bonding, and Delinquent Behavior

\begin{tabular}{|c|c|c|c|c|c|c|c|c|c|}
\hline & GS & MO & PC & PA & PP & MC & MA & MP & TD \\
\hline General Self (GS) & 1 & $.512^{* *}$ & $.369^{* *}$ & $-.225^{\star *}$ & .026 & $.361^{* *}$ & $-.224^{\star *}$ & -.025 & .008 \\
\hline Moral Self (MO) & & 1 & $.315^{\star *}$ & $-.193^{* *}$ & .031 & $.204^{* *}$ & $-.170^{*}$ & -.040 & $-.157^{*}$ \\
\hline Paternal Care (PC) & & & 1 & $-.390^{* *}$ & .043 & $.614^{* *}$ & $-.348^{* *}$ & -.087 & -.134 \\
\hline Paternal Authoritarianism (PA) & & & & 1 & $.360^{* *}$ & $-.357^{* *}$ & $.676^{\star *}$ & $.179^{*}$ & .038 \\
\hline Paternal Protectiveness (PP) & & & & & 1 & -.067 & $.253^{* *}$ & $.612^{* *}$ & .132 \\
\hline Maternal Care (MC) & & & & & & 1 & $-.506^{\star *}$ & -.040 & -.108 \\
\hline Maternal Authoritarianism (MA) & & & & & & & 1 & $.383^{* *}$ & -.036 \\
\hline Maternal Protectiveness (MP) & & & & & & & & 1 & -.072 \\
\hline Total Delinquency (TD) & & & & & & & & & 1 \\
\hline
\end{tabular}

${ }^{*} p<.05,{ }^{* *} p<.01$

$=-.23$ and -.22 respectively). For correlations within the $\mathrm{PBI}$ subscales, the pattern of correlations among the three maternal subscales was similar as those among the three paternal subscales, and the pattern was also similar for the male as for the females samples. In short, authoritarianism was negatively correlated with care but positively with protectionism, bur protectionism and care was not correlated. Nevertheless, when analyzed separately for the males and females samples, the correlations between delinquency and other variables were quite different. For the male participants, only paternal protectionism was significantly correlated with delinquency $(r=.22, p<$ .05). But for the female participants, their level of delinquency was correlated with a range of variables including self-esteem (-.27), paternal caring (-.35) and maternal caring (-.38), paternal authoritarian (.31) and maternal authoritarian (.30).

In order to control for the effects of gender and other demographic variables, a stepwise multiple regression analysis was conducted. Demographic variables (gender, age, household income) were entered in Step One, followed by the predictor variables (general self-esteem, moral self, father's and mother's authoritarianism, care, protectionism) in Step Two (Table 3). Results suggested that delinquency was predicted by gender $(\beta=-.38, p<.01)$ but not by age

Table 3: Multiple Regression Analysis of Delinquency Predicted by Demographic Variables, Self-Esteem, Moral Self, and Parental Bonding Measure (all Samples)

\begin{tabular}{|c|c|c|c|c|}
\hline $\begin{array}{c}\text { Model } \\
\text { Predictor Variables }\end{array}$ & Std. $\beta$ & SE & $\boldsymbol{R}$ & $R^{2}$ change \\
\hline Step 1 & & & .39 & $0.154^{\star * *}$ \\
\hline Sex & $-.382^{* * *}$ & 1.36 & & \\
\hline Age & -.048 & 0.26 & & \\
\hline Income & -.046 & 0.61 & & \\
\hline Step 2 & & & .49 & $.089^{* *}$ \\
\hline Sex & $-.379^{* * *}$ & 1.41 & & \\
\hline Age & -.056 & 0.26 & & \\
\hline Income & -.053 & 0.61 & & \\
\hline Self-esteem & .059 & .135 & & \\
\hline Moral self & $-.187^{*}$ & .181 & & \\
\hline Paternal Authoritarianism & -.214 & .417 & & \\
\hline Paternal Caring & -.139 & .194 & & \\
\hline Paternal Protectionism & $.260^{*}$ & .342 & & \\
\hline Maternal Authoritarianism & -.003 & .457 & & \\
\hline Maternal Caring & -.065 & .238 & & \\
\hline Maternal Protectionism & -.051 & .332 & & \\
\hline
\end{tabular}

${ }^{\star} p<.05,{ }^{* *} p<.01,{ }^{* \star *} p<.001$. 
or household income, this model has accounted for $15.4 \%$ of total variance in delinquency. To summarize, male participants tended to manifest more delinquent behaviors than females did, while age and income did not have significant predictive effect on delinquency. By adding the self variables (self-esteem, moral self) and the parental bonding variables to the model (Step 2), the regression model has increased $8.9 \%$ additional variance in explaining total delinquency. Among the self and the parental variables, moral self $(\beta=-.19, p<$ $.05)$, and paternal protectionism $(\beta=.26, p<.05)$ significantly predicted delinquency (while effect of gender was controlled), but other variables (authoritarianism, care) were not predictive of delinquency.

\section{DISCUSSION}

The hypothesis that self-concept should be negatively correlated with delinquency was partially supported. Moral self was found to be associated with delinquency, while general self (self-esteem) was not predictive of delinquency in general. By including both the general and moral facets of self-esteem, this study has confirmed that the linkage between self-concept and delinquency should be domain specific. The effect of gender was significant, it alone has accounted for $15 \%$ of variance in delinquency. After controlling the effect of gender, moral self and father's protectionism were still significantly predicting delinquency. Moral self was found to be associated negatively with delinquency, meaning that people who have lower moral self would have higher delinquency. This finding concurs with the studies of Tarry and Emler (2007) and Cheng (2014). Tarry and Emler (2007) found evidence supporting the notion that delinquency was negatively associated with moral values. In another study on Chinese people in Hong Kong, Cheng (2014) found that moral self was predictive of different kinds of delinquency, such as gambling, gangsters and bullying, sexual misconduct. To summarize, domain specific self-concept (such as moral self or social self) rather than a generic measure of self-esteem should be used in future research.

Another focus of the present study is about the association between parental bonding and delinquency. Our study has confirmed that some parental factors should be accountable for child's delinquency. Among the three aspects of parental bonding (care, authoritarianism, protectionism), only paternal protectionism was significantly associated with delinquency. Other aspects of parental bonding were not associated with delinquency. The effect of father's protectionism was strong and significant, even after the effect of gender being controlled. This finding has further clarified the previous research about the effects of parenting and family relation on delinquency (e.g. Hoeve et al. 2009; Huey et al., 2000). Our study shows that parent's care and authoritarianism may not predict delinquency as believed, at least not among Hong Kong Chinese people, but father's over-protection did show strong direct effect on delinquency. This finding shows that the linkage between authoritarian parenting and delinquency may not be always true. Alternatively, the effects of family and parental relationship may be culture specific.

Findings from Gunnoe, Hetherington and Reiss (2006) revealed that the impact of authoritarian parent was different among families of different religious backgrounds. Gunnoe and colleagues found that authoritarian parenting could predict externalizing and internalizing problems for adolescents in Conservative Protestant families but not for adolescents in control families. Research findings from Quoss and Zhao (1995) revealed that while children could be dissatisfied with their family rules, they were generally satisfied with the parent-child relationship that they perceived to be authoritarian. A high level of authoritarianism does not necessarily be associated with delinquency or other negative outcomes. As stated by Van Campen and Russell (2010), "parenting that leads to optimal development for adolescents can differ by culture in important ways" (p. 4). Van Campen and Russell (2010) also highlighted that although authoritative parenting can be beneficial, it is not necessarily more beneficial than authoritarian parenting in some ethnic groups. They pointed out that the first-generation Chinese youths from authoritarian homes did just as well in school as those from authoritative homes. As Chao (1994) argued, scoring high on measures of authoritarian should not have the same meaning for Chinese as for European-Americans. Therefore, how children interpret and perceive authoritarian parenting style, rather than authoritarian parenting practices per se, may have more impact on parent-child relationship and children's well-being.

\section{CONCLUSION}

This study has provided evidence on the negative association between moral self and delinquency, and the positive association between paternal overprotection and delinquency. However, a global measure of self-esteem (general self) may not be 
predictive of delinquency, while self-evaluation on the moral domain should be indicative of a person's delinquent behaviors. While authoritarian and high controlling parents are believed to be disadvantageous of child development, our study shows that overprotection of parents (especially father's) is of serious concern.

\section{LIMITATION AND SUGGESTIONS}

This study has a number of limitations. The study adopted a cross-sectional instead of a longitudinal approach. While moral self was found to be a significant predictor of delinquency in this study, previous research has shown that delinquency was correlated with subsequent self-esteem (Lee \& Lee, 2012), which suggested that the relationship between self-esteem and delinquency can be reciprocal. A longitudinal approach will provide more information on the relationship between self-concept, parenting and delinquency and how they may interact with one another. Second, gender differences were found on correlations between delinquency and a range of self and parental bonding. While gender difference was not one of the focuses of the present study, our regression analysis showed that gender has accounted for around $15 \%$ of variance in predicting delinquency. How parenting affects delinquency for men and women differently would worth further studies. More in-depth research on how the three $\mathrm{PBI}$ dimensions of mothers and fathers are related to males' and females' delinquency separately may shed light on how parenting can be used as an effective protective factor on youth delinquency. This study did not focus on how maternal and paternal parenting styles interact. While there are benefits of separately examined the parenting styles or behaviors of fathers and mothers (Hoeve et al., 2011), it will be beneficial for future studies to investigate the combined effect of maternal and paternal parenting styles on boys and girls and how different combinations may have affected their delinquency. Thirdly, respondents were to report their feeling about parental bonding in this study. This approach may have the limitation of observer bias or subjective bias. The measurement may be more objective if peer- and/or parent-report measurement can be included. Due to this limitation, the parenting experience reported in this study can be arguably understood as the parental bonding from the child's perspective. A dyadic approach (parent-child) in measuring the parental bonding may shed different lights on the topic in future studies.

\section{Appendix 1: Behavior Checklist}

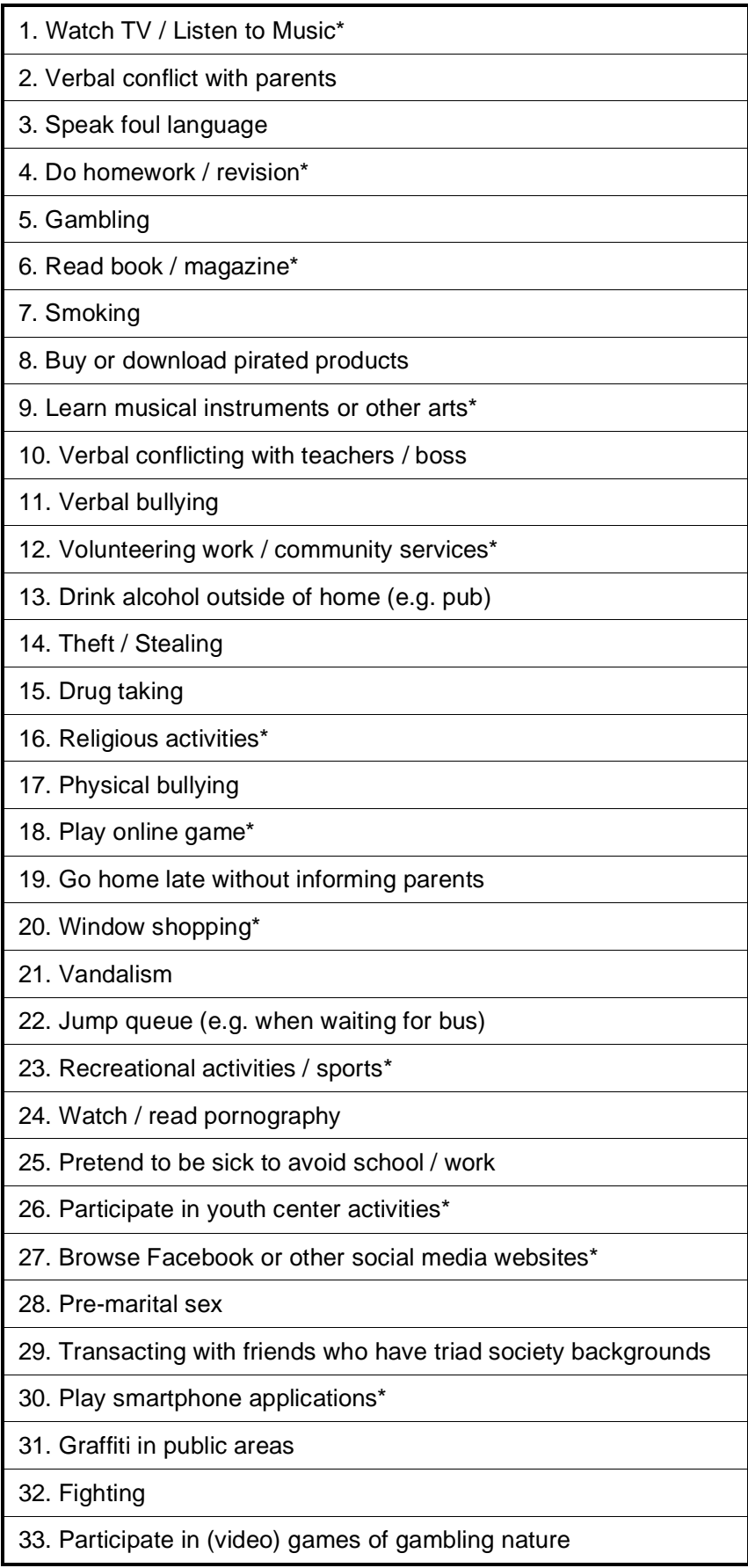

${ }^{*}$ Note: Items with star $\left(^{*}\right)$ are excluded for the computation of Total Delinquency.

\section{REFERENCES}

Ainsworth, M., Blehar, M. C., Waters, E., \& Wall, S. (1978). Patterns of Attachment: A psychological study of the Strange Situation.

Baumrind, D. (1971). Current patterns of parental authority. Developmental Psychology, 4(1), 1-103. http://dx.doi.org/10.1037/h0030372

Bowlby, J. (1969, 1973, 1980). Attachment and Loss (Vol.1 to Vol.3). New York: Basic Books. 
Caldwell, R. M., Beutler, L. E., Ross, S. A., \& Silver, N. C. (2006). Brief report: An examination of the relationships between parental monitoring, self-esteem and delinquency among mexican american male adolescents. Journal of Adolescence, 29(3), 459-464. http://dx.doi.org/10.1016/j.adolescence.2005.07.005

Chambers, J. A., Power, K. G., Loucks, N., \& Swanson, V. (2000). Psychometric properties of the parental bonding instrument and its association with psychological distress in a group of incarcerated young offenders in Scotland. Social Psychiatry and Psychiatric Epidemiology, 35(7), 318-325. http://dx.doi.org/10.1007/s001270050245

Chao, R. K. (1994). Beyond parental control and authoritarian parenting style: Understanding Chinese parenting through the cultural notion of training. Child Development, 65(4), 1111. http://dx.doi.org/10.2307/1131308

Cheng, C.H.K. (1997). Self-conceptions of Hong Kong Adolescents: Conceptual, Measurement, and Process Perspectives. Unpublished $\mathrm{PhD}$ manuscript submitted to the University of Hong Kong. Hong Kong.

Cheng, C.H.K. (2014). The Predictive Effects of Self-Esteem, Moral Self, and Moral Reasoning on Delinquent Behaviors of Hong Kong Young People. International Journal of Criminology and Sociology, 2014, 3, 133-145.

http://dx.doi.org/10.6000/1929-4409.2014.03.12

Cheng, C. H. K., \& Watkins, D. (2000). Age and gender invariance of self-concept factor structure: An investigation of a newly developed Chinese self-concept instrument. International Journal of Psychology, 35(5), 186-193. http://dx.doi.org/10.1080/00207590050171120

Cheung, Y. W. (1997). Family, school, peer, and media predictors of adolescent deviant behavior in hong kong. Journal of Youth and Adolescence, 26(5), 569-596. http://dx.doi.org/10.1023/A:1024534022895

Cheung, N. W., T., \& Cheung, Y. W. (2008). Self-control, social factors, and delinquency: A test of the general theory of crime among adolescents in hong kong. Journal of Youth and Adolescence, 37(4), 412-430.

http://dx.doi.org/10.1007/s10964-007-9218-y

Church, Wesley T.,,II, Tomek, S., Bolland, K. A., Hooper, L. M., Jaggers, J., \& Bolland, J. M. (2012). A longitudinal examination of predictors of delinquency: An analysis of data from the mobile youth survey. Children and Youth Services Review, 34(12), 2400-2408. http://dx.doi.org/10.1016/i.childyouth.2012.09.007

Cox, B. J., Enns, M. W., \& Clara, I. P. (2000). The parental bonding instrument: Confirmatory evidence for a three-factor model in a psychiatric clinical sample and in the national comorbidity survey. Social Psychiatry and Psychiatric Epidemiology, 35(8), 353-357. http://dx.doi.org/10.1007/s001270050250

Donnellan, M. B., Trzesniewski, K. H., Robins, R. W., Moffitt, T. E., \& Caspi, A. (2005). Low self-esteem is related to aggression, antisocial behavior, and delinquency. Psychological Science, 16(4), 328-335.

http://dx.doi.org/10.1111/j.0956-7976.2005.01535.x

EMB. (2003). Users' and Training Manual for Measuring Secondary Students' Performance in Affective and Social Domains. Hong Kong: The Education and Manpower Bureau, Government of Hong Kong SAR.

Fergusson, D. M., Horwood, L. J., \& Ridder, E. M. (2005). Show me the child at seven: The consequences of conduct problems in childhood for psychosocial functioning in adulthood. Journal of Child Psychology and Psychiatry, 46(8), 837-849. http://dx.doi.org/10.1111/j.1469-7610.2004.00387.x

Gao, J., Li, Y., Cai, Y., Chen, J., Shen, Y, Tao, M. (2012). Perceived parenting and risk for major depression in Chinese women. Psychological Medicine, 42(5), 921-30. http://dx.doi.org/10.1017/S0033291711001942
García, F., \& Gracia, E. (2009). Is always authoritative the optimum parenting style? evidence from spanish families. Adolescence, 44(173), 101-131. Retrieved from $\mathrm{http}: / /$ search.proquest.com/docview/621909838?accountid=1 0134

Gunnoe, M. L., Hetherington, E. M., \& Reiss, D. (2006). Differential impact of fathers' authoritarian parenting on early adolescent adjustment in conservative protestant versus other families. Journal of Family Psychology, 20(4), 589-596. http://dx.doi.org/10.1037/0893-3200.20.4.589

Hardy, S. A., Walker, L. J., Olsen, J. A., Woodbury, R. D., \& Hickman, J. R. (2014). Moral identity as moral ideal self: Links to adolescent outcomes. Developmental Psychology, $50(1), 45-57$. http://dx.doi.org/10.1037/a0033598

Hoeve, M., Dubas, J. S., Eichelsheim, V. I., van der Laan, P.,H., Smeenk, W., Gerris, J. R., \& M. (2009). The relationship between parenting and delinquency: A meta-analysis. Journal of Abnormal Child Psychology, 37(6), 749-75. http://dx.doi.org/10.1007/s10802-009-9310-8

Hoeve, M., Dubas, J. S., Gerris, J. R. M., van, d. L., \& Smeenk, W. (2011). Maternal and paternal parenting styles: Unique and combined links to adolescent and early adult delinquency. Journal of Adolescence, 34(5), 813-827. http://dx.doi.org/10.1016/j.adolescence.2011.02.004

Huey, S.J., Henggeler, S.W., Brondino, M.J., \& Pickrel, S.G. 2000 Mechanisms of Change in Multisystemic Therapy: Reducing Delinquent Behavior through Therapist Adherence and Improved Family and Peer Functioning. Journal of Consulting and Clinical Psychology, 68(3):451-467. http://dx.doi.org/10.1037/0022-006X.68.3.451

Kendler, K. S. (1996). Parenting: A genetic-epidemiologic perspective. The American Journal of Psychiatry, 153(1), 1120.

http://dx.doi.org/10.1176/ajp.153.1.11

Le, T. N., Monfared, G., \& Stockdale, G. D. (2005). The relationship of school, parent, and peer contextual factors with selfreported delinquency for Chinese, Cambodian, Laotian or Mien, and Vietnamese youth. Crime and Delinquency, 51(2), 192-219. http://dx.doi.org/10.1177/0011128704273472

Lee, K., \& Lee, J. (2012). Self-esteem and delinquency in South Korean adolescents: Latent growth modeling. School Psychology International, 33(1), 54-68. http://dx.doi.org/10.1177/0143034311409856

Lichtenstein, P., Ganiban, J., Neiderhiser, J. M., Pedersen, N. L., Hansson, K., Cederblad, M., Reiss, D. (2003). Remembered parental bonding in adult twins: Genetic and environmental influences. Behavior Genetics, 33(4), 397-408. http://dx.doi.org/10.1023/A:1025317409086

Lo, T.W., Cheng, C.H.K., Wong, D.S.W., Rochelle, T.L., and Kwok, S.I. 2011. "Self-esteem, Self-efficacy and Deviant Behavior of Young People in Hong Kong." Advances in Applied Sociology, 1:48-55. http://dx.doi.org/10.4236/aasoci.2011.11004

Martínez, I., García, J. F., \& Yubero, S. (2007). Parenting styles and adolescents' self-esteem in Brazil. Psychological Reports, 100(3), 731-745. http://dx.doi.org/10.2466/pr0.100.3.731-745

Mason, W. A., Hitch, J. E., Kosterman, R., McCarty, C. A Herrenkohl, T. L., \& Hawkins, J. D. (2010). Growth in adolescent delinquency and alcohol use in relations to young adult crime, alcohol use disorders, and risky sex: A comparison of youth from low- versus middle-income backgrounds. Journal of Child Psychology and Psychiatry, 51(12), 1377-1385 http://dx.doi.org/10.1111/j.1469-7610.2010.02292.x

Maziti, E. (2014). The relationship between parenting styles and selfesteem among adolescents: A case of zimunya high school (manicaland). Asian Journal of Research in Social Sciences 
and Humanities, 4(2), 27-41. Retrieved from http://search. proquest.com/docview/1504534760?accountid=10134

Parker, G. (1990). The Parental Bonding Instrument: A decade of research. Social Psychiatry and Psychiatric Epidemiology, 25, 281-282.

Parker, G., Tupling, H., \& Brown, L. B. (1979). A parental bonding instrument. The British Journal of Medical Psychology, 52(1), $1-10$.

http://dx.doi.org/10.1111/j.2044-8341.1979.tb02487.x

Police in Figures (n.d.). Retrieved from http://www.police.gov.hk/ ppp_en/09_statistics/index.html

Quoss, B., \& Zhao, W. (1995). Parenting styles and children's satisfaction with parenting in china and the United States. Journal of Comparative Family Studies, 26(2), 265. Retrieved from http://search.proquest.com/docview/232576808? accountid $=10134$

Sartaj, B., \& Aslam, N. (2010). Role of authoritative and authoritarian parenting in home, health and emotional adjustment. Journal of Behavioral Sciences, 20(1), 47-66. Retrieved from http://search.proquest.com/docview/612886697? accountid=1 0134

Shu, B. C., Lo, W. J., \& Lung, F. W. (1999). The reliability and validity of a Chinese version of the Parental Bonding Instrument. The Journal of Nursing Research, 7, 479-489.

Sroufe, L. A. (2005). Attachment and development: A prospective, longitudinal study from birth to adulthood. Attachment and Human Development, 7(4), 349-367. http://dx.doi.org/10.1080/14616730500365928

Sroufe, L. A., Egeland, B., Carlson, E., \& Collins, W. A. (2005). The development of the person: The Minnesota study of risk and adaptation from birth to adulthood. New York: Guilford.
Stoltz, S., van Londen, M., Dekovic, M., Prinzie, P., de Castro, B.,O., \& Lochman, J. E. (2013). Simultaneously testing parenting and social cognitions in children at-risk for aggressive behavior problems: Sex differences and ethnic similarities. Journal of Child and Family Studies, 22(7), 922-931. http://dx.doi.org/10.1007/s10826-012-9651-8

Strage, A., \& Brandt, T. S. (1999). Authoritative parenting and college students' academic adjustment and success. Journal of Educational Psychology, 91(1), 146-156. http://dx.doi.org/10.1037/0022-0663.91.1.146

Tarry, H., \& Emler, N. (2007). Attitude, values and moral reasoning as predictors of delinquency. British Journal of Developmental Psychology, 25(2), 169-183. http://dx.doi.org/10.1348/026151006X113671

Van Campen, K. S., \& Russell, S. T. (2010). Cultural differences in parenting practices: What Asian American families can teach us. Retrieved from http://mcclellandinstitute.arizona.edu/ sites/mcclellandinstitute.arizona.edu/files/ResearchLink_2.1_ Russell_AsianFam.pdf

Van de Schoot, R. \& Wong, T. M. L. (2012). Do delinquent young adults have a high or a low level of self-concept? Self and Identity, 11(2), 148. http://dx.doi.org/10.1080/15298868.2010.517713

Wan, Y.Y.T. (2012). Cognitive and emotional determinants of delinquent behavior. S S Student E-Journal, 1, 42-59. Retrieved from http://ssweb.cityu.edu.hk/download/RS/EJournal/journal3.pdf

Wong, S. W., \& Watkins, D. (2001). Self-esteem of ability grouping: A Hong Kong investigation of the Big Fish Little Pond Effect. Educational Psychology, 21(1), 79-87. http://dx.doi.org/10.1080/01443410123082

DOI: http://dx.doi.org/10.6000/1929-4409.2015.04.12

(C) 2015 Cheng and Cheng; Licensee Lifescience Global.

This is an open access article licensed under the terms of the Creative Commons Attribution Non-Commercial License (http://creativecommons.org/licenses/by-nc/3.0/) which permits unrestricted, non-commercial use, distribution and reproduction in any medium, provided the work is properly cited. 